\title{
NỒNG ĐÔ 25-HYDROXY VITAMIN D HUYẾT TƯƠNG VÀ CÁC YỂ TỐ NGUY CƠ CỦA HộI CHÚNG CHUYỂN HÓA
}

Nguyễn Trọng Nghĩa ${ }^{1}$, Nguyễn Thị Nhạn ${ }^{2}$, Đào Thị Dù̀a ${ }^{3}$, Trần Hũu An $n^{3}$, Phạm Trung Hiếu

(1) Nghiên cứu sinh Trưòng Đại học Y Dược Huế, chuyên ngành Nội khoa (2) Bộ môn Nội, Truờng Đại học Y Dược Huế

(3) Bệnh viện Trung ưong Huế

\section{ABSTRACT \\ Plasma 25-hydroxyvitamin D concentration and risk factors for metabolic syndrome}

Background: The metabolic syndrome (MS) is a constellation of cardiometabolic risk factors that tend to cluster together in affected individuals more often than predicted by chance. The presence of the MS substantially increases the risk of developing type 2 diabetes and cardiovascular disease, and is associated with a range of adverse clinical outcomes, many of which are closely associated with aging. Recent studies show that low vitamin D status is very common in the world and this is a risk factor of MS. Objective: (1). Plasma 25-hydroxyvitamin D concentration in subjects with MS. (2). Relationship between plasma 25hydroxyvitamin $\mathrm{D}$ concentration and risk factors for MS. Materials and methods: A cross-sectional study with control group on 275 adult subjects for health examinations at International Medical Center at Hue Central Hospital, including 94 subjects with MS and control group of 181 healthy subjects. MS was defined according to the IDF, NHLBI, AHA, WHF, IAS, IASO (2009). Plasma hydroxyvitamin D concentration was measured using chemiluminescent microparticle immunoassay. Results: Plasma 25-hydroxyvitamin $\mathrm{D}$ concentration in subjects with MS was $27,8 \mathrm{ng} / \mathrm{mL}$, incidence of plasma 25-hydroxyvitamin D deficiency $(87,2 \%)$ was significantly higher than in control group $(24,9 \%)(\mathrm{p}<0,001)$. The plasma 25-hydroxyvitamin $\mathrm{D}$ concentration was inverse correlation with waist circumference, BMI, total cholesterol, triglycerid, reduce
HDL-C, systolic blood pressure, diastolic blood pressureand HbA1C $(\mathrm{p}<0,05$ to $\mathrm{p}<0,001)$. Conclusions: The plasma 25hydroxyvitamin $\mathrm{D}$ concentration at subjects with MS was $27,8 \mathrm{ng} / \mathrm{mL}$ and the incidence of 25-hydroxyvitamin D deficiency in the MS group was $87,2 \%$. The plasma 25hydroxyvitamin $\mathrm{D}$ concentration was inverse correlation with waist circumference, BMI, total cholesterol, triglycerid, reduce HDL-C, systolic blood pressure, diastolic blood pressure and $\mathrm{HbA} 1 \mathrm{C}$.

Key words: Metabolic syndrome, 25hydroxyvitamin $D$.

\section{TÓM TẮT}

Đặt vấn đề: Hội chứng chuyển hóa ( $\mathrm{HCCH}$ ) là một tập hợp của các yếu tố nguy cơ chuyển hóa tim, có khuynh hướng nhóm lại với nhau ở các đối tượng bị ảnh hưởng hơn là dự đoán một cách tình cờ. Sự hiện diện của $\mathrm{HCCH}$ làm tăng đáng kể nguy cơ xuất hiện đái tháo đường típ 2 , bệnh tim mạch, từ đó liên quan chặt chẽ đến quá trình lão hóa và một loạt các kết cục xấu. Các nghiên cứu gần đây cho thấy thiếu vitamin $\mathrm{D}$ rất phổ biến trên thế giới và là một yếu tố nguy cơ của $\mathrm{HCCH}$. Mục tiêu nghiên cứu: (1). Đặc điểm nồng độ 25-hydroxyvitamin $\mathrm{D}$ huyết tương ở đối tượng có $\mathrm{HCCH}$. (2). Mối liên quan giữa nồng độ 25 -hydroxyvitamin $\mathrm{D}$ huyết tương và các yếu tố nguy cơ của $\mathrm{HCCH}$. Đối tượng và phương pháp nghiên cứu: Sử dụng phương pháp nghiên cứu mô tả cắt ngang có đối chứng ở 275 đối tượng người trưởng thành đến khám sức khỏe tại Trung tâm điều trị theo yêu cầu và quốc tế - Bệnh viện Trung ương Huế, trong đó nhóm bệnh gồm 94 đối tượng có $\mathrm{HCCH}$ và nhóm chứng gồm 181 người 
khỏe mạnh. HCCH được chẩn đoán theo đồng thuận của các tổ chức IDF, NHLBI, AHA, WHF, IAS, IASO năm 2009. Nồng độ 25-

hydroxyvitamin $\mathrm{D}$ được đo bằng phương pháp xét nghiệm miễn dịchvi hạt hóa phát quang. Kết quả: Nồng độ 25-hydroxyvitamin D huyết tương ở đối tượng có $\mathrm{HCCH}$ là 27,8 $\mathrm{ng} / \mathrm{mL}$, tỷ lệ giảm 25-hydroxyvitamin $\mathrm{D}$ huyết tương là $87,2 \%$ cao hơn nhóm chứng là $24,9 \%$ có ý nghĩa thống kê $(\mathrm{p}<0,001)$. Có mối tương quan nghịch giữa nồng độ 25hydroxyvitamin $\mathrm{D}$ huyết tương với vòng bụng, BMI, cholesterol toàn phần, triglycerid, giảm HDL-C, huyết áp tâm thu, huyết áp tâm trương và $\mathrm{HbA} 1 \mathrm{C}(\mathrm{p}<0,05$ đến $\mathrm{p}<0,001)$. Kết luận: Nồng độ 25-hydroxyvitamin $\mathrm{D}$ huyết tương ở đối tượng có $\mathrm{HCCH}$ là 27,8 ng/mL, tỷ lệ giảm 25-hydroxyvitamin $\mathrm{D}$ huyết tương là $87,2 \%$. Có mối tương quan nghịch giữa nồng độ 25-hydroxyvitamin $\mathrm{D}$ huyết tương với vòng bụng, $\mathrm{BMI}$, cholesterol toàn phần, triglycerid, giảm HDL-C, huyết áp tâm thu, huyết áp tâm trương và $\mathrm{HbA} 1 \mathrm{C}$.

Tù khóa: Hội chứng chuyển hóa, 25hydroxyvitamin $D$.

Chịu trách nhiệm chính: Nguyễn Trọng Nghĩa

Ngày nhận bài: 16/11/2019

Ngày phản biện khoa học: 20/12/2019

Ngày duyệt bài: 31/12/2019

\section{1. ĐĂT VẤN ĐỀ}

Hội chứng chuyển hóa $(\mathrm{HCCH})$ là một tập hợp của các yếu tố nguy cơ chuyển hóa tim, có khuynh hướng nhóm lại với nhau ở các đối tượng bị ảnh hưởng hơn là dự đoán một cách tình cờ. Sự hiện diện của $\mathrm{HCCH}$ làm tăng đáng kể nguy cơ xuất hiện đái tháo đường típ 2, bệnh tim mạch, từ đó liên quan chặt chẽ đến quá trình lão hóa và một loạt các kết cục xấu. Ước tính hiện tại có khoảng 20-25\% dân số thế giới bị ảnh hưởng bởi $\mathrm{HCCH}$, tỷ lệ mắc $\mathrm{HCCH}$ tăng theo độ tuổi và có hơn $45 \%$ số người trên 60 tuổi có $\mathrm{HCCH}$ [11]. Ở Việt Nam, trong một nghiên cứu dân số đô thị ở thành phố Hồ Chí Minh cho thấy tỷ lệ mắc $\mathrm{HCCH}$ là $12 \%$ ở người trưởng thành [12], một nghiên cứu khác trong nhóm dân số trung niên ở vùng đồng bằng sông Hồng cho thấy tỷ lệ mắc $\mathrm{HCCH}$ là $16,3 \%$ [3] và trong một nghiên cứu ở khu vực nông thôn Thừa Thiên Huế cho thấy tỷ lệ người dân mắc $\mathrm{HCCH}$ là 19,2\% [2].

Béo phì, đặc biệt là béo trung tâm hay béo thể nội tạng với sự lắng đọng lipid trong gan là một đặc điểm cốt lõi của hội chứng chuyển hóa [11]. Năng lượng được dự trữ quá mức trong mô mỡ và các cơ quan khác dưới dạng lipid, dễ gây ngộ độc lipid và tình trạng viêm do chuyển hóa, từ đó hoạt hóa các protein kinase trong tế bào và gây tổn thương các thành phần tín hiệu của insulin, và hậu quả là gây kháng insulin. Kháng insulin là nguyên nhân chủ yếu gây $\mathrm{HCCH}$, một nhóm các rối loạn có mối tương quan với nhau, bao gồm béo phì, tăng glucose máu, rối loạn lipid máu và tăng huyết áp [18].

Thiếu vitamin $\mathrm{D}$ đang gia tăng ở mức độ toàn cầu và có liên quan đến tăng nguy cơ mắc các bệnh khác nhau.Hoạt động phân tử của vitamin $\mathrm{D}$ có liên quan đến việc duy trì nồng độ khi nghỉ bình thường của các dạng oxy hoạt động và $\mathrm{Ca}^{2+}$, không chỉ trong các tế bào, mà còn trong các mô đáp ứng với insulin. Cả hai hoạt động qua gen và không qua gen của vitamin $\mathrm{D}$ đều hướng đến tín hiệu insulin. Qua đó, vitamin $\mathrm{D}$ làm giảm mức độ bệnh lý liênquan đến kháng insulin như stress oxy hóa và viêm. [20]. Mối liên quan giữa giảm nồng độ vitamin $\mathrm{D}$ trong $\mathrm{HCCH}$ đã được chứng minh qua nhiều nghiên cứu. Vì vậy, chúng tôi thực hiện đề tài "Nồng độ 25hydroxyvitamin $\mathrm{D}$ huyết tương và các yếu tố nguy cơ của hội chứng chuyển hóa" với mục tiêu sau: (1). Đặc điểm nồng độ 25hydroxyvitamin D huyết tuơng ở đối tượng có họi chứng chuyển hóa. (2). Mối liên quan giữa nồng độ 25-hydroxyvitamin D huyết tương và các yếu tố nguy cơ của hội chứng chuyển hóa.

\section{2. ĐỐI TƯợNG VÀ PHƯƠNG PHÁP NGHIÊN CÚU}

Đối tượng nghiên cứu: Gồm 275 đối tượng người trưởng thành đi khám sức khỏe, chia làm 2 nhóm:

- Nhóm bệnh: 94 đối tượng có $\mathrm{HCCH}$. Chẩn đoán $\mathrm{HCCH}$ dựa theo tuyên bố đồng 
thuận của IDF, NHLBI, AHA, WHF, IAS, IASO năm 2009 [1]: khi có ít nhất 3 trong 5 yếu tố sau: Tăng vòng bụng: vòng bụng $\geq 90 \mathrm{~cm}$ đối với nam, $\geq 80 \mathrm{~cm}$ đối với nữ. Tăng triglycerid máu $\geq 150 \mathrm{mg} / \mathrm{dl} \quad(\geq 1,7 \mathrm{mmol} / 1)$, hoặc đã được chẩn đoán và điều trị. Giảm HDL-Cholesterol máu $<40 \mathrm{mg} / \mathrm{dl} \quad(1,03$ $\mathrm{mmol} / \mathrm{l})$ đối với nam: $<50 \mathrm{mg} / \mathrm{dl}$ $(<1,29 \mathrm{mmol} / \mathrm{l})$ đối với nữ, hoặc đã được chẩn đoán và điều trị. Huyết áp tăng $\geq 130 / 85$ $m m H g$ hoặc tăng huyết áp đã được chẩn đoán và điều trị. Tăng glucose máu lúc đói $\geq 100$ $\mathrm{mg} / \mathrm{dl}(\geq 5,6 \mathrm{mmol} / \mathrm{l})$, hoặc đái tháo đường típ 2 đã được chẩn đoán và điều trị.

Tiêu chuẩn loại trừ: Các đối tượng không đồng ý tham gia nghiên cứu, đang mang thai, đang sử dụng các thuốc có chứa vitamin $\mathrm{D}$, đang mắc các bệnh cấp tính, các đối tượng có các bệnh lý mạn tính nặng: xơ gan, suy thận mạn, dùng corticoid dài ngày ( $>1$ tháng), các đối tượng bị dị tật vùng bụng, cột sống lồng ngực, các đối tượng không thể tự đứng được, các đối tượng giảm sút trí tuệ nặng.

- Nhóm chứng: 181 người khỏe mạnh có cùng độ tuổi và giới so với nhóm bệnh và không có hội chứng chuyển hóa, đồng ý tham gia nghiên cứu.

Phương pháp nghiên cứu: Mô tả cắt ngang có đối chứng. Các biến số nghiên cứu bao gồm tuổi, giới, chỉ số nhân trắc, các thành tố của $\mathrm{HCCH}$ và nồng độ 25 -hydroxyvitamin $\mathrm{D}$ (25-OH-D) huyết tương được đo bằng phương pháp xét nghiệm miễn dịchvi hạt hóa phát quang được tiến hành tại Trung tâm điều trị theo yêu cầu và quốc tế - Bệnh viện Trung ương Huế, chúng tôi chọn mốc tứ phân vị thấp nhất ở nhóm chứng làm giá trị giảm nồng độ 25-OH-D $(27,8 \mathrm{ng} / \mathrm{mL})$.

Cõ̃ mẫu: Lấy mẫu thuận tiện.

Xử lý và phân tích số liệu: Bằng phương pháp thống kê y học và sử dụng phần mềm SPSS 22.0.

\section{KẾT QUẢ NGHIÊN CÚU}

Nghiên cứu trên 94 đối tượng có $\mathrm{HCCH}$ và 181 người khỏe mạnh làm nhóm chứng, chúng tôi ghi nhận một số kết quả như sau:

Bảng 3.1. Đặc điểm nhóm nghiên cứu

\begin{tabular}{|c|c|c|c|c|c|}
\hline & Thông số & $\begin{array}{l}\text { Chung } \\
(\mathrm{N}=275)\end{array}$ & $\begin{array}{c}\text { Nhóm bệnh } \\
(\mathrm{n}=94)\end{array}$ & $\begin{array}{c}\text { Nhóm chứng } \\
(\mathrm{n}=181)\end{array}$ & $\mathrm{p}$ \\
\hline & Nữ, $(n, \%)$ & $144(52,4)$ & $57(60,6)$ & $87(48,1)$ & \\
\hline G10゙1 & Nam, $(\mathrm{n}, \%)$ & $131(47,6)$ & $37(39,4)$ & $94(51,9)$ & $<0,0 \mathbf{b}$ \\
\hline Tuổi (năm), & $\pm S D$ & $49,56 \pm 12,56$ & $52,23 \pm 13,64$ & $48,17 \pm 11,76$ & $<0,05$ \\
\hline BMI, $X \pm S$ & & $23,35 \pm 2,96$ & $25,04 \pm 2,55$ & $22,47 \pm 2,78$ & $<0,001$ \\
\hline Vòng bụng & m), $X \pm S D$ & $81,54 \pm 9,70$ & $88,73 \pm 6,46$ & $77,81 \pm 8,98$ & $<0,001$ \\
\hline HATT $(\mathrm{mm}$ & $\mathrm{X} \pm \mathrm{SD}$ & $121,24 \pm 22,47$ & $138,35 \pm 22,38$ & $112,35 \pm 16,66$ & $<0,001$ \\
\hline $\operatorname{HATTr}(\mathrm{mm}$ & g), $\bar{X} \pm S D$ & $73,29 \pm 10,71$ & $79,89 \pm 10,00$ & $69,86 \pm 9,41$ & $<0,001$ \\
\hline Cholesterol $^{7}$ & $(\mathrm{mmol} / \mathrm{l}), \mathrm{X} \pm \mathrm{SD}$ & $5,32 \pm 1,21$ & $5,71 \pm 1,29$ & $5,11 \pm 1,12$ & $<0,001$ \\
\hline & $X \pm S D$ & $1,97 \pm 1,38$ & $2,68 \pm 1,66$ & $1,61 \pm 1,05$ & - \\
\hline$(\mathrm{mmol} / \mathrm{l})$ & $\begin{array}{l}\text { Trung vị } \\
\text { (khoảng tứ phân vị) }\end{array}$ & $\begin{array}{c}1,59 \\
(1,05-2,32)\end{array}$ & $\begin{array}{c}2,23 \\
(1,77-3,36)\end{array}$ & $\begin{array}{c}1,30 \\
(0,93-1,99)\end{array}$ & $<0,001$ \\
\hline HDL-C (mn & $1 / 1), \bar{X} \pm S D$ & $1,22 \pm 0,29$ & $1,13 \pm 0,24$ & $1,27 \pm 0,30$ & $<0,001$ \\
\hline LDL-C (mn & $1 / 1), \bar{X} \pm S D$ & $3,29 \pm 1,01$ & $3,52 \pm 1,11$ & $3,17 \pm 0,94$ & $<0,01$ \\
\hline Glucose $(\mathrm{m}$ & $\mathrm{Dl} / \mathrm{l}), \mathrm{X} \pm \mathrm{SD}$ & $5,56 \pm 1,15$ & $6,00 \pm 1,22$ & $5,34 \pm 1,04$ & $<0,001$ \\
\hline $\operatorname{HbA} 1 \mathrm{C}(\%)$ & & $5,68 \pm 0,72$ & $5,97 \pm 0,85$ & $5,53 \pm 0,58$ & $<0,001$ \\
\hline
\end{tabular}

Nhận xét: Có sự khác biệt có ý nghĩa thống kê giữa nhóm bệnh và nhóm chứng về tuối, giới và các yếu tố nguy cơ $(\mathrm{p}<0,05$ đến $\mathrm{p}<0,001)$. 
Bảng 3.2. Nồng độ 25-hydroxyvitamin D huyết tương nhóm nghiên cứu.

\begin{tabular}{|l|l|c|c|c|c|}
\hline \multicolumn{2}{|c|}{ Thông số } & $\begin{array}{c}\text { Chung } \\
(\mathrm{N}=275)\end{array}$ & $\begin{array}{c}\text { Nhóm bệnh } \\
(\mathrm{n}=94)\end{array}$ & $\begin{array}{c}\text { Nhóm chứng } \\
(\mathrm{n}=181)\end{array}$ & $\mathrm{p}$ \\
\hline \multirow{4}{*}{$\begin{array}{l}\text { 25-OH-D } \\
\text { (ng/ml) }\end{array}$} & \multicolumn{1}{|c|}{$\mathrm{X} \pm$ SD } & $29,88 \pm 8,24$ & $22,78 \pm 3,57$ & $33,56 \pm 7,55$ & - \\
\cline { 2 - 6 } & $\begin{array}{l}\text { Trung vị } \\
\text { (khoảng tứ phân vị) }\end{array}$ & $\begin{array}{c}28,30 \\
(24,50-34,30)\end{array}$ & $\begin{array}{c}23,05 \\
(20,68-25,63)\end{array}$ & $\begin{array}{c}32,10 \\
(\mathbf{2 7 , 8 0}-37,50)\end{array}$ & $<\mathbf{0 , 0 0 1}$ \\
\cline { 2 - 6 } & Không giảm, (n,\%) & $140(50,9)$ & $12(12,8)$ & $136(75,1)$ & $<\mathbf{0 , 0 0 1}$ \\
\cline { 2 - 6 } & Giảm, (n,\%) & $135(49,1)$ & $82(87,2)$ & $45(24,9)$ & \\
\hline
\end{tabular}

Nhận xét: Chúng tôi chọn mốc giảm 25-OH-D là $27,80 \mathrm{ng} / \mathrm{mL}$. Tỷ lệ giảm 25-OH-D ở nhóm bệnh cao hơn nhóm chứng có ý nghĩa thống kê $(\mathrm{p}<0,001)$.

Bảng 3.3. Mối tương quan giữa nồng độ 25-hydroxyvitamin D huyết tuoơng với các yếu tố nguy cơ của hội chứng chuyển hóa.

\begin{tabular}{|l|c|c|}
\hline \multicolumn{1}{|c|}{ Yếu tố } & r & p \\
\hline Tuổi $($ năm $)$ & 0,005 & $>0,05$ \\
\hline Vòng bụng $(\mathrm{cm})$ & $-0,205$ & $<\mathbf{0 , 0 1}$ \\
\hline BMI $\left(\mathrm{kg} / \mathrm{m}^{2}\right)$ & $-0,172$ & $<\mathbf{0 , 0 1}$ \\
\hline Cholesteroltoàn phần $(\mathrm{mmol} / \mathrm{L})$ & $-0,131$ & $<\mathbf{0 , 0 5}$ \\
\hline Triglycerid $(\mathrm{mmol} / \mathrm{L})$ & $-0,152$ & $<\mathbf{0 , 0 5}$ \\
\hline HDL-C $(\mathrm{mmol} / \mathrm{L})$ & 0,138 & $<\mathbf{0 , 0 5}$ \\
\hline LDL-C $(\mathrm{mmol} / \mathrm{L})$ & $-0,114$ & $>0,05$ \\
\hline HATT $(\mathrm{mmHg})$ & $-0,255$ & $<\mathbf{0 , 0 0 1}$ \\
\hline HATTr $(\mathrm{mmHg})$ & $-0,146$ & $<\mathbf{0 , 0 5}$ \\
\hline Glucose $(\mathrm{mmol} / \mathrm{L})$ & $-0,115$ & $>0,05$ \\
\hline HbA1c $(\%)$ & $-0,161$ & $<\mathbf{0 , 0 1}$ \\
\hline
\end{tabular}

Nhận xét: có mối tương quan nghịch mức độ yếu giữa nồng độ $25-\mathrm{OH}-\mathrm{D}$ và các yếu tố: vòng bụng, BMI, Cholesterol TP, Triglycerid, giảm HDL-C, HATT, HATTr và HbAlc có ý nghĩa thống kê $(\mathrm{p}<0,05$ đến $\mathrm{p}<0,001)$.

\section{BÀN LUẬN}

Trong nghiên cứu của chúng tôi ghi nhận ở 94 đối tượng có hội chứng chuyển hóa cho thấy nồng độ $25-\mathrm{OH}-\mathrm{D} \mathrm{D}$ là $27,8 \mathrm{ng} / \mathrm{ml}$ và tỷ lệ giảm 25-OH-D là $87,2 \%$. Các nghiên cứu trên thế giới có thể theo hệ số tham chiếu của một số hiệp hội, tổ chức y tế đã phát triển các hướng dẫn về tình trạng vitamin $\mathrm{D}$ nhằm xác định tình trạng thiếu hụt, không đủ và đủ vitamin $\mathrm{D}$ hoặc chọn trị trung bình hay chọn mốc tứ phân vị thấp nhất của nồng độ $25-\mathrm{OH}-$ $\mathrm{D}$ ở nhóm chứng để xác định giá trị giảm 25 OH-D như trong nghiên cứu của chúng tôi. Nghiên cứu của Junling Fu và cộng sự (2018) ở các đối tượng từ 18-28 tuổi có nguy cơ mắc
$\mathrm{HCCH}$ sống ở Bắc Kinh ghi nhận nồng độ 25-OH-D ở nhóm $\mathrm{HCCH}$ là 12,49 (10,34$18,28) \mathrm{ng} / \mathrm{mL}$ thấp hơn nhóm không $\mathrm{HCCH}$ là $14,21(11,08-19,09) \mathrm{ng} / \mathrm{mL}$ có ý nghĩa thống kê $(\mathrm{p}<0,005)$ và có tỷ lệ thiếu hụt vitamin $\mathrm{D}$ (nồng độ 25-OH-D <20 ng/mL) ở nhóm $\mathrm{HCCH}$ là 80,7\% [4]. Joanna Mitri và cộng sự (2014) thực hiện nghiên cứu 25hydroxyvitamin $\mathrm{D}$ huyết tương và nguy cơ HCCHở người Mỹ gốc châu Ả trên 25 tuổi ghi nhận trị trung bình nồng độ $25-\mathrm{OH}-\mathrm{D}$ nhóm $\mathrm{HCCH}$ là 20,9 $(9,4) \mathrm{ng} / \mathrm{mL}$ thấp hơn nhóm không HCCH là $23,2(10,3) \mathrm{ng} / \mathrm{mL}$ có ý nghĩa thống kê $(\mathrm{p}<0,0001)$ và tỷ lệ giảm 25 OH-D ở nhóm HCCH là 75,7\% [16]. Nghiên 
cứu của Claudia Gagnon và cộng sự (2012)về nồng độ 25-OH-D thấp có liên quan đến tăng nguy cơ phát triển $\mathrm{HCCH}$ sau 5 năm ở người Úc trưởng thành ghi nhận trị trung bình nồng độ 25-OH-D nhóm HCCH là 25 (9) ng/mL thấp hơn nhóm không $\mathrm{HCCH}$ là 27 (10) $\mathrm{ng} / \mathrm{mL}$ có ý nghĩa thống kê $(\mathrm{p}<0,001)$ và tăng nguy cơ phát triển hội chứng chuyển hóa là $141 \%$ và $174 \%$ ở các đối tượng có nồng độ $25-\mathrm{OH}-\mathrm{D}<18 \mathrm{ng} / \mathrm{mL}$ và $18-23 \mathrm{ng} / \mathrm{mL}$ [6]. Trong nghiên cứu ở Bắc Kinh của Yanhui Lu và cộng sự (2015) về nồng độ 25hydroxyvitamin $\mathrm{D}$ thấp và nguy cơ mắc hội chứng chuyển hóa ở người Trung Quốc trưởng thành ghi nhận trị trung bình nồng độ 25-OH-D nhóm HCCH là $15,13(6,23) \mathrm{ng} / \mathrm{mL}$ thấp hơn nhóm không $\mathrm{HCCH}$ là $19,48(8,62)$ $\mathrm{ng} / \mathrm{mL}$ có ý nghĩa thống kê $(\mathrm{p}<0,0001)$ và có tỷ lệ thiếu hụt vitamin $\mathrm{D}$ (nồng độ 25-OH-D $<20 \mathrm{ng} / \mathrm{mL}$ ) ở nhóm HCCH là 82,07\% [14]. Chúng tôi nhận định nồng độ25hydroxyvitamin $\mathrm{D}$ và tỷ lệ thiếu vitamin $\mathrm{D}$ có nhiều trị số kết quả khác nhau có thể phụ thuộc đối tượng nghiên cứu, chủng tộc, vĩ độ, mùa, labo xét nghiệm, phương pháp định lượng và lựa chọn tiêu chuẩn chẩn đoán thiếu vitamin D.

Từ kết quả của các nghiên cứu trên cho chúng ta thấy tỷ lệ thiếu vitamin $\mathrm{D}$ cao hơn ở người có hội chứng chuyển hóa. Dữ liệu dịch tê̂ học cho thấy thiếu vitamin $D$ trong các quần thể khác nhau đã trở thành một hiện tượng phổ biến. Người ta cho rằng giảm nồng độ vitamin này trong máu có thể tương quan với sự xuất hiện của bệnh lý chuyển hóa. Các khiếm khuyết dạng hydroxyl hóa của vitamin $\mathrm{D}$, cũng như nồng độ thấp đáng kể phần vitamin $\mathrm{D}$ có khả dụng sinh học được phát hiện nhiều hơn trong nhóm người có hội chứng chuyển hóa. Cơ chế đằng sau giảm nồng độ 25-OH-D trong bệnh béo phì thể nội tạng (cơ sở để chẩn đoán hội chứng chuyển hóa) vẫn chưa được làm rõ hoàn toàn [17].

Trong nghiên cứu của chúng tôi ghi nhận có mối tương quan nghịch giữa nồng độ 25 hydroxyvitamin $\mathrm{D}$ huyết tương với vòng bụng, BMI, cholesterol toàn phần, triglycerid, giảm HDL-C, huyết áp tâm thu, huyết áp tâm trương và HbA1c có ý nghĩa thống kê ( $\mathrm{p}<0,05$ đến $\mathrm{p}<0,001)$. Kết quả này tương đương với nghiên cứu Robert $\mathrm{S}$. Tepper và cộng sự (2014) nhằm xác định ngưỡng thiếu vitamin D liên quan đến các dấu hiệu chuyển hóa tim ghi nhận BMI, vòng bụng, insulin đói, HOMA-IR, TG, hs-CRP, huyết áp tâm trương và tâm thu có mối liên quan nghịch với nồng độ 25-OH-D huyết thanh và đề xuất ngưỡng nồng độ $25-\mathrm{OH}-\mathrm{D}$ là $11-14 \mathrm{ng} / \mathrm{mL}$ có liên quan đến các chỉ số chuyển hóa tim [21]. Nghiên cứu của Joanna Mitri và cộng sự (2014) sau khi điều chỉnh đa biến, những người tham gia ở nhóm có tứ phân vị $25-\mathrm{OH}-$ $\mathrm{D}$ cao nhất có tỷ lệ mắc hội chứng chuyển hóa thấp hơn, chu vi vòng bụng nhỏ hơn, HLD-C cao hơn và glucose huyết tương thấp hơn so với những người tham gia có tứ phân vị 25$\mathrm{OH}-\mathrm{D}$ thấp nhất, nồng độ $25-\mathrm{OH}-\mathrm{D}$ huyết tương cao hơn có liên quan đến độ nhạy insulin lớn hơn và tiết insulin thấp hơn [16].Nghiên cứu của Claudia Gagnon và cộng sự (2012)ghi nhận nồng độ25-OH-D huyết thanh có liên quan nghịch với chu vi vòng bụng, triglycerid, glucose lúc đói và HOMAIR. Thiếu hụt và không đủ vitamin $\mathrm{D}$ có liên quan đến sự gia tăng nguy cơ hội chứng chuyển hóa, chu vi vòng bụng, triglycerid, glucose lúc đói, và kháng insulin cao hơn sau 5 năm [6].Các nghiên cứu cắt ngang trước đây ở người lớn và trẻ em cũng đã báo cáo nồng độ 25-hydroxyvitamin $\mathrm{D}$ có liên quan nghịch với vòng bụng [10], [5]. Mối liên quan tích cực giữa các mức độ khác nhau của $\mathrm{BMI}$ và tình trạng thiếu vitamin $\mathrm{D}$ ở cả người lớn và trẻ em đã được chứng minh. Cơ chế phân tử của mối liên quan giữa béo phì và tình trạng thiếu vitamin $\mathrm{D}$ là tác động của vitamin $\mathrm{D}$ trong điều hòa biểu hiện gen liên quan đến quá trình tạo mỡ, viêm, stress oxy hóa và chuyển hóa ở các tế bào mỡ trưởng thành [19]. Một số nghiên cứu cho thấy mối liên quan giữa tình trạng vitamin $\mathrm{D}$ thấp và xơ vữa động mạch do rối loạn lipid máu đặc trưng bởi tăng nồng độ triglycerid, giảm HDL-C và LDL-C nhỏ, đậm đặc. Các cơ chế giải thích mối liên quan giữa thiếu vitamin $\mathrm{D}$ và rối loạn lipid máu bao gồm tác dụng điều hòa của 
vitamin $\mathrm{D}$ đối với biệt hóa mô mỡ và ức chế lipoprotein lipase, và ảnh hưởng của vitamin $\mathrm{D}$ trên kháng insulin và các chất điều hòa chính của chuyển hóa lipid như PPAR- $\delta$ [15]. Một số nghiên cứu cho thấy vitamin $\mathrm{D}$ giúp duy trì cân bằng nội môi glucose thông qua xác định mối liên quan nghịch giữa nồng độ 25-hydroxyvitamin $D$ và kháng insulin, insulin máu đói, glucose máu đói, HbA1C [13],[8], [5], [6].

Nghiên cứu của chúng tôi còn có các hạn chế nhất định vì đây là một nghiên cứu cắt ngang. Một phân tích tổng hợp đã cho thấy mối tương quan giữa tình trạng vitamin $\mathrm{D}$ trong máu và tỷ lệ mắc $\mathrm{HCCH}$ trong dân số trưởng thành nói chung đã được thiết lập trong các nghiên cứu cắt ngang. Tuy nhiên, mối liên quan đáng kể đã không được tái tạo trong các nghiên cứu dọc [9]. Ngoài ra, chúng tôi không thể xem xét các yếu tố như nồng độ calci, hormon tuyến cận giáp có thể ảnh hưởng đến nồng độ vitamin $\mathrm{D}$ trong máu. Điểm mạnh của nghiên cứu này là các đối tượng chủ yếu chỉ đi khám sức khỏe, vì thế tình trạng vitamin $\mathrm{D}$ và các thông số sinh hóa liên quan đến $\mathrm{HCCH}$ được phản ánh đúng hơn các đối tượng là người bệnh nhập viện.

\section{KẾT LUÂN}

Nồng độ 25-hydroxyvitamin D huyết tương ở đối tượng có hội chứng chuyển hóa là $27,8 \mathrm{ng} / \mathrm{ml}$, tỷ lệ giảm 25-hydroxyvitamin $\mathrm{D}$ huyết tương là $87,2 \%$.

Có mối tương quan nghịch giữa nồng độ 25-hydroxyvitamin $\mathrm{D}$ huyết tương với vòng bụng, BMI, cholesterol toàn phần, triglycerid, giảm HDL-C, huyết áp tâm thu, huyết áp tâm trương và $\mathrm{HbA} 1 \mathrm{C}$.

\section{TÀI LIỆ THAM KHẢO}

1. Bộ Y tế (2013), Nội tiết chuyển hóa, Nhà xuất bản Y học, tr 355

2. Nguyễn Thị Hường, Đoàn Phước Thuộc, Lê Văn Chi (2018), Giá trị của vòng bụng và tỷ vòng bụng/vòng mông trong tiên đoán hội chứng chuyển hóa của người dân tại hai xã của huyện Quảng Điền, tỉnh Thừa Thiên Huế, Tạp chí Y Dược hoc, tập 8, số $6, \operatorname{tr}$ 27-33

3. Binh TQ, Phuong PT, Nhung BT (2014), "Metabolic syndrome among a middleaged population in the Red River Delta region of Vietnam", BMC endocrine disorders. 14 (1), pp. 77

4. Fu J, Han L, Zhao Y, Li G, Zhu Y, Li Y et al (2018), "Vitamin D levels are associated with metabolic syndrome in adolescents and young adults: The BCAMS study", Clinical Nutrition. 38 (5), pp. 2161-2167

5. Gagnon C, Lu ZX, Magliano DJ, Dunstan DW, Shaw JE, Zimmet PZ, et al et al (2011), "Serum 25-Hydroxyvitamin D, Calcium Intake, and Risk of Type 2 Diabetes After 5 Years", Results from a national, population-based prospective study (the Australian Diabetes, Obesity and Lifestyle study). 34 (5), pp. 11331138.

6. Gagnon C, Lu ZX, Magliano DJ, Dunstan DW, Shaw JE, Zimmet PZ et al (2012), "Low serum 25-hydroxyvitamin $\mathrm{D}$ is associated with increased risk of the development of the metabolic syndrome at five years: results from a national, population-based prospective study (The Australian Diabetes, Obesity and Lifestyle Study: AusDiab)", The Journal of Clinical Endocrinology \& Metabolism. 97 (6), pp. 1953-1961.

7. Ganji V, Zhang X, Shaikh N, Tangpricha $V$ et al (2011), "Serum 25hydroxyvitamin D concentrations are associated with prevalence of metabolic syndrome and various cardiometabolic risk factors in US children and adolescents based on assay-adjusted serum 25-hydroxyvitamin D data from NHANES 2001-2006", The American journal of clinical nutrition. 94 (1), pp. 225-233

8. Hyppönen E, Boucher BJ, Berry DJ, Power C (2008), "25-hydroxyvitamin D, IGF-1, and metabolic syndrome at 45 
years of age: a cross-sectional study in the 1958 British Birth Cohort", Diabetes. 57

(2), pp. 298-305

9. Ju, S. Y., Jeong, H. S., Kim, D. H, et al. (2014), "Blood vitamin D status and metabolic syndrome in the general adult population: a dose-response metaanalysis", J Clin Endocrinol Metab. 99 (3), pp. 1053-1063

10. Kim MK, Il Kang M, Won Oh K, Kwon HS, Lee JH, Lee WC et al. (2010), "ORIGINAL ARTICLE: The association of serum vitamin D level with presence of metabolic syndrome and hypertension in middle-aged Korean subjects", Clinical Endocrinology. 73 (3), pp. 330-338

11. Krentz AJ, Scuteri A (2017), "Insulin resistance and the metabolic syndrome", Diabetes in Old Age, pp. 177-212

12. Kunii D, Hung NTK, Sakai T, Yamamoto $S$ et al (2005), "The metabolic syndrome: prevalence and risk factors in the urban population of Ho Chi Minh City", Diabetes research and clinical practice. 67 (3), pp. 243-250

13. Lu L, Yu Z, Pan A, Hu FB, Franco OH, Li $\mathrm{H}$ et al (2009), "Plasma 25Hydroxyvitamin D Concentration and Metabolic Syndrome Among MiddleAged and Elderly Chinese Individuals", Diabetes care. 32 (7), pp. 1278-1283

14. Lu Y,Liu M, Pei Y, Li J, Tian H, Cheng X et al (2015), "Low levels of serum 25hydroxyvitamin $\mathrm{D}$ and risk of metabolic syndrome in China", International journal of clinical and experimental medicine. 8 (8), pp. 13790
15. Miñambres I, Sanchez-Quesada JL, Pérez A (2015), "The association between hypovitaminosis D and metabolic syndrome: current understanding", Clinical Lipidology. 10 (6), pp. 513-524.

16. Mitri J, Nelson J, Ruthazer R, Garganta C, Nathan DM, Hu FB et al (2014), "Plasma 25-hydroxyvitamin D and risk of metabolic syndrome: an ancillary analysis in the Diabetes Prevention Program", European journal of clinical nutrition. 68 (3), pp. 376.

17. Pelczyńska, M., Grzelak, T., Sperling, M., et al. (2017). "Impact of 25hydroxyvitamin $\mathrm{D}$, free and bioavailable fractions of vitamin $\mathrm{D}$, and vitamin $\mathrm{D}$ binding protein levels on metabolic syndrome components" Archives of medical science: AMS 13(4): 745.

18. Error! Reference source not found.

19. Ruiz-Ojeda FJ, Anguita-Ruiz A, Leis R, Aguilera CM (2018), "Genetic Factors and Molecular Mechanisms of Vitamin D and Obesity Relationship", Annals of Nutrition and Metabolism, pp. 89-99.

20. Szymczak-Pajor I, Śliwińska A (2019), "Analysis of Association between Vitamin D Deficiency and Insulin Resistance", Nutrients. 11 (4), pp. 794

21. Tepper S, Shahar D, Geva D, Avizohar O, Nodelman M, Segal E et al (2014), "Identifying the threshold for vitamin D insufficiency in relation to cardiometabolic markers", Nutrition, Metabolism and Cardiovascular Diseases. 24 (5), pp. 489-494. 